\title{
Por que eu não vou à biblioteca?: discursos, representações e sentimentos desvelados por sujeitos escolares através de desenhos
}

\author{
Why don't I go to the library?: discourses, representations and loving feelings for school \\ subjects through drawings
}

\author{
Lucas Veras de Andrade \\ Licenciado em Pedagogia. Bacharel em Biblioteconomia. Especialista em Supervisão Educacional. \\ Docente da rede Municipal de Teresina. \\ E-mail: lukkandrade18@hotmail.com
}

\section{Resumo}

Pretendemos com esta investigação apresentar o desenho como um recurso subjetivo, onde a criança projeta de modo espontâneo suas experiências. A partir destas produções, analisamos discursos e representações como fatores que motivam um grupo de crianças a minimizarem o interesse em frequentar a biblioteca da instituição escolar em que estão vinculados. O estudo compreendeu como lócus uma escola de ensino fundamental da rede municipal de Teresina (PI), tendo como participantes um grupo de estudantes que foram selecionados segundo critérios, posteriormente, descritos. Assim, a coleta de dados considerou grafismos (desenhos), tendo como procedimento complementar a entrevista. Logo, os resultados demonstram vários aspectos que na visão dos discentes diminuem o seu interesse em relação ao espaço em discussão. Desse modo, esperamos que os resultados redirecionem o significado deste ambiente na instituição de análise e contribua para aprimorar o alcance das ações educacionais.

Palavras Chaves: Desenhos Infantis. Biblioteca Escolar. Alunos - Ensino Fundamental.

\begin{abstract}
We intend with this investigation present the drawing as a subjective feature, where your child designs so spontaneous experiences. From these productions, we analyze speeches and representations as factors that motivate a group of children to minimise the interest in attending school attending institution library. The study understood as elementary school locus of the municipal network of Teresina (PI), with participants a group of students who were selected on the basis of criteria described thereafter. Thus, data collection was considered artwork (drawings), with supplementary procedure to interview. Soon, the results demonstrate several aspects which in the view of students decrease their interest in relation to the space for discussion. Thus, we expect the results to redirect the meaning of this environment at the institution and analysis contributes to enhance the reach of educational actions.
\end{abstract}

Key Words: Children's Drawings. School Library. Student - Elementary School. 


\section{Introdução}

O estudo em questão é resultado de inquietações desencadeadas ao longo de minha formação em Biblioteconomia e, especificamente, na minha atividade profissional como educador. No ano de 2007, por cursar Licenciatura em Pedagogia me inseri no lócus escolar, assim, percebi a inexistência do ambiente da biblioteca, e quando existente apresentava-se pouco contributivo para a aprendizagem e desenvolvimento de competências dos alunos.

Após alguns meses do ano mencionado, ingressei no curso de Biblioteconomia, então compreendi os objetivos e a importância deste espaço na escola. No decorrer do curso, vivenciei atividades empíricas em algumas bibliotecas e observei o quanto é difícil alcançar metas e desenvolver atividades, principalmente, na biblioteca escolar, em especial quando esta se vincula ao poder público.

Durante este percurso imprimi esforços para que se concretizasse um trabalho eficiente, de modo a acarretar benefícios para todos os atores das escolas em que desenvolvi minhas atividades, seja como docente ou estagiário de Biblioteconomia, entretanto, algumas barreiras emergiram, principalmente, quando percebi que somente teoria e o anseio de transformar não seriam suficientes para um trabalho efetivo e concreto, precisaria procurar parcerias nas instituições de ensino.

Ao término das referidas graduações no ano de 2012, ingressei no magistério público como efetivo. Na escola, para qual fui designado logo percebi que a realidade frente à biblioteca era o mesmo ou até mais precário dos anteriores que vivenciei. No período em questão, durante a formação ofertada aos docentes de Língua Portuguesa, disciplina que ministro na Secretaria Municipal de Educação de Teresina (PI), fui estimulado a desenvolver um projeto educativo que envolvesse leitura e o gênero textual lenda, por conta das comemorações e festividades referentes ao folclore.

Então, vi uma oportunidade fecunda de aliar os conhecimentos oriundos de minhas formações, desse modo, pude desenvolver práticas na biblioteca e chamar atenção para este espaço, uma vez que a culminância final da formação seria a apresentação dos projetos dos cursistas no I Seminário de Socialização de Experiências com Projetos do Centro de Formação Continuada para docentes no Centro de Formação Odilon Nunes da Secretaria Municipal de Educação de Teresina (SEMEC), e neste evento estariam autoridades que poderiam contribuir com a mudança da realidade, até então explanada.

Bibl. Esc. em R., Ribeirão Preto, v. 3, n. 2, p. 72-93, 2015. 
Por que eu não vou à biblioteca?: discursos, representações e sentimentos desvelados por sujeitos escolares através de desenhos

No período de planejamento do projeto, elaborei atividades diversificadas que envolviam o desenvolvimento de várias habilidades nos alunos como: criação, leitura, escrita, interpretação, entre outras. Entretanto, na execução percebemos um árduo caminho a ser percorrido, pois a biblioteca da escola guardava os materiais de educação física, os livros encontravam-se empoeirados, empilhados e mal organizados, portanto, antes que se realizassem qualquer atividade era necessário "arrumar a casa".

E nessa perspectiva continuamos nosso trabalho por meio da construção de outro projeto que teve por finalidade uma intervenção pedagógica no espaço da biblioteca. Neste reorganizamos o ambiente, limpamos todos os livros, fizemos a diferenciação dos diversos suportes informacionais. Ainda, conseguimos a compra de mobiliário a partir do convencimento e sensibilização da direção da escola sobre esta necessidade, elaboramos através da classificação em cores um sistema de recuperação da informação (aspecto significativo quanto ao acervo da escola, já que tivemos dificuldade em encontrar referenciais para a elaboração do projeto de lenda por conta da desorganização).

Quando retornarmos ao foco inicial, as atividades elaboradas foram desenvolvidas sem maiores entraves resultando em entusiasmo de parcela dos alunos e o conhecimento dos outros sobre aquele espaço, pois por meio de questionário aplicado sobre a satisfação dos alunos a respeito do projeto lenda, nos foi proferido pela maioria o desconhecimento sobre o ambiente da biblioteca e seus objetivos, configurando assim a nosso ver, uma realidade ainda mais preocupante do que imaginávamos.

Após a finalização de ambos os projetos, explicamos aos alunos e professores da referida escola, como ocorreria o funcionamento da biblioteca, a forma do empréstimo, expusemos aos professores atividades passíveis de serem realizadas, como trabalhar as mesmas no espaço e principalmente como aconteceria a busca de exemplares no acervo pelos seus usuários, no intuito de manter o ambiente organizado, uma vez que a escola não dispõe de um profissional responsável e específico para trabalhar neste setor.

Como consequência observamos interesse e a presença de alunos de forma autônoma no espaço, sem que estivessem auxiliados pela intervenção de um mediador. Entretanto, nossa iniciativa não foi suficiente para consolidar a presença constante da biblioteca na escola e na formação do alunado, principalmente, destes que tiveram a iniciativa de frequetarem a biblioteca por iniciativa própria. 
Lucas Veras de Andrade

Como diz o ditado "uma andorinha só não faz verão". Por pouco tempo percebemos a mobilização dos docentes em prol dos objetivos que discutimos na apresentação do projeto de dar vida à biblioteca. Logo após, notamos uma inferior procura pelo espaço por estes mesmos alunos. No decorrer do ano estes chegaram até nós, da mesma maneira que procuraram a biblioteca e nos revelaram não quererem mais ir ao encontro dos livros e da biblioteca sem manifestar as motivações, uma contradição no comportamento antes demonstrado.

No primeiro momento não questionamos as atitudes destes alunos, uma vez que o número destes se mostrava irrelevante dentro do universo das turmas que o proponente deste relato era titular, mas na medida em que a demanda aumentou significativamente, ou seja, um percentual de vinte alunos em um total de noventa e seis, começamos a nos preocupar e querer desvelar as motivações que geraram nestes, sentimentos de descontentamento a ponto de apresentarem comportamentos contrários à atitude inicial.

Desse modo, nossa investigação tem como objetivo: revelar as motivações que um grupo de alunos tem para não quererem frequentar o espaço da biblioteca de sua escola. Lembrando que nosso objetivo foi elaborado segundo o controverso comportamento apresentado pelos alunos na situação acima apresentada.

$\mathrm{O}$ estudo se torna relevante à medida que seus resultados procuram redirecionar $\mathrm{o}$ olhar dos agentes educacionais e em específico o da escola analisada sobre o ambiente da biblioteca escolar no sentido de ressignificarem os comportamentos demonstrados tanto pelos alunos como pelos os membros da escola. A pesquisa contribui para as discussões do ambiente educacional por demonstrar por meio de discursos de alunos um novo viés da problemática do mau funcionamento de bibliotecas, uma vez que em nossas leituras, esta problemática é mais vista pelo aspecto estrutural e burocrático e nunca pela perspectiva do aluno.

Dessa forma, o estudo está estruturado em tópicos. Sendo o primeiro a introdução, onde relatamos como ocorreu o encontro com a temática da pesquisa e tecemos as primeiras reflexões sobre a realidade do espaço da biblioteca escolar. No segundo apresentamos breves considerações sobre o desenho infantil, que é entendido por nós como uma atribuição de sentido, uma realidade conceitual, uma percepção do objeto através do olhar de quem produz, e cujo entendimento está contido em seu próprio autor. 
Por que eu não vou à biblioteca?: discursos, representações e sentimentos desvelados por sujeitos escolares através de desenhos

No terceiro, abordaremos o percurso metodológico. Neste pontuaremos o delineamento das ações em favor da consecução do objetivo proposto, elencando métodos, o lócus empírico, participantes e todos os procedimentos necessários para o desenvolvimento do estudo. No quarto, apresentaremos os dados e as discussões, e por último, temos as considerações finais, onde retomamos as discussões, com o intuito de ampliá-las tecendo algumas estratégias que possivelmente possibilitarão mudanças na realidade evidenciada.

\section{O desenho como forma de expressão em crianças: breves considerações}

É por meio do desenho que muitas vezes a criança demonstra o seu desenvolvimento e estabelece uma relação dialógica entre o conhecer/reconhecer o que a cerca, desenvolvendo assim, o "eu ser" no mundo. O desenho representa a forma como a criança encontra para consolidar sua comunicação com alguém, nele está expresso sua compreensão de mundo, onde denunciam e envolvem, criando o seu mundo singular, repleto de representações e intencionalidades.

Vygostski (1998) compreende o desenho infantil como a capacidade de criação do homem. Para o autor, as crianças não desenham aquilo que está no seu campo visual, e sim o conhecimento que emerge a cerca do seu saber frente aos objetos. Lima e Carvalho (2008) nessa perspectiva nos demonstram que as crianças na elaboração de seus desenhos são capazes de externar pensamentos, conhecimentos e suas interpretações, sejam elas em situações experienciadas ou mesmo imaginadas.

Sendo o desenho o reflexo do conhecimento da criança e o produto final (a imagem) à realidade conceitual, Natividade, Coutinho e Zanella (2008, p. 10) afirmam que "a importância não incide sobre o produto, mas sim na significação que o autor atribui ao próprio processo de desenhar e sobre o que é possível compreender da realidade a partir da imagem produzida".

As autoras nos chamam atenção para duas nuances manifestadas nos traços dos desenhos infantis: a fantasia e o lado real. Ao tempo em que a criança expressa um lado fantástico, ela nos evidencia uma realidade que é advinda de suas experiências. Nessa conjuntura o desenho pode ser entendido a partir da perspectiva histórico/social. Em concordância ao exposto Natividade, Coutinho e Zanella (2008) ratificam que o desenho é constituído socialmente, uma vez que o individuo é entendido como um ser social em sua Bibl. Esc. em R., Ribeirão Preto, v. 3, n. 2, p. 72-93, 2015. 
Lucas Veras de Andrade

gênese, e sendo assim, toda a sua atividade é igualmente entendida e estabelecida em suas relações com o outro.

Nessa linha de pensamento Vygostski (1998) analisa o desenho infantil a partir do contexto histórico/cultural na qual a criança está imersa. Em consonância ao pensamento dele, Ferreira (2001, p. 35) afirma que o desenho infantil é "“[...] resultante da vivência destes com objetos reais, sendo mediado pela palavra e pela interação com o 'outro"”.

A autora acima pontua um aspecto importante na construção do desenho que é a palavra, e nesta construção demonstramos ainda a linguagem entendida por nós como um processo cognitivo e psicológico. Natividade, Coutinho e Zanella (2008) evidenciam os processos psicológicos envolvidos na construção de um desenho por crianças, destacando a imaginação, memória, emoção, entre outros e principalmente, a interdependência destes na construção dos desenhos. Nesse sentido, o desenho infantil não deve ser entendido apenas como representação ou expressão da realidade, mas também como um produto cheio de intencionalidades que envolvem aspectos emocionais e cognitivos.

Para a compreensão dos desenhos infantis é imprescindível o acompanhamento da sua criação e compreender o que motivou a construção daquele traçado como produto final. É importante também ressaltar a importância da escuta de seu autor, pois somente ele é capaz de traduzir fielmente os signos e significados estabelecidos no papel grafado. Silva (2010) em relação à interpretação de desenhos explica que significa esclarecer, extrair um significado oculto, transferindo a mensagem produzida para a linguagem verbal. Por fim, o desenho é uma importante ferramenta no desenvolvimento da criança que proporciona o desenvolvimento de sua capacidade criativa e cognitiva. 
Por que eu não vou à biblioteca?: discursos, representações e sentimentos desvelados por sujeitos escolares através de desenhos

Metodologia

O estudo é considerado como qualitativo, do tipo estudo de caso, que na perspectiva de (LÜDKE; ANDRÉ, 1986, p. 18-20) dentre suas várias conceituações afirmam ser estudos que visam uma 'interpretação em contexto'.

Inicialmente, elaboramos e executamos uma oficina sobre a biblioteca para os alunos da turma, na qual éramos titulares. Na finalização, apresentamos um questionário, onde os alunos pontuariam motivações de irem ou não ao ambiente em questão, assim como apresentariam alterações que segundo eles eram necessárias para a melhor utilização do espaço, lembrando que estes eram alunos do $4^{\circ}$ e $5^{\circ}$ anos do Ensino Fundamental, com faixa etária entre nove e onze anos.

O intuito da oficina era compreender as motivações e os sentidos dados por aqueles que como já citado, apresentaram comportamentos dissonantes em relação ao ambiente em discussão e apresentaram reclamações sobre situações que vivenciaram na escola e no contexto da biblioteca que os impulsionaram a desenvolverem tais atitudes.

De um total de noventa e seis questionários, vinte foram selecionados (referente aos vinte alunos que como também já mencionado, buscaram o espaço da biblioteca após os projetos e intervenção por iniciativa própria). Após análise destes, vimos que não fomos bem sucedidos, uma vez que os discursos apontaram respostas que não representavam conteúdo passível de categorização para análise.

Então, em um segundo momento, em nosso horário pedagógico na escola, propusemos a estes vinte alunos escolhidos anteriormente, produções de desenhos em conjunto com as aulas de desenho artístico que a escola oferece através do projeto Mais Educação.

Desse modo, o desenho figurou como instrumento para a coleta dos dados, que segundo Natividade, Coutinho e Zanella (2008) é um canal privilegiado de comunicação, expressão e propício à utilização pelo público infantil. Na oficina específica para a produção dos desenhos para a pesquisa, os alunos foram questionados sobre o gostar de desenhar. Como devolutiva tivemos o aspecto afirmativo por todos, o que facilitou o diálogo entre nós e eles. Posteriormente, os mesmos foram instigados a partir do questionamento: por que eu não vou à biblioteca da minha escola? a confeccionarem seus desenhos. 
Lucas Veras de Andrade

Do universo das produções, escolhemos oito por apresentarem elementos que se destacaram no universo produzido pelos discentes e apresentaram elementos que se diferenciaram entre as demais, ainda que pontuando elementos dos outros doze.

Sendo assim, o universo analisado é representado por desenhos elaborados por três crianças do sexo feminino e cinco do sexo masculino com idade entre nove e dez anos. Como forma de complementar o conhecimento exposto nos desenhos utilizamos a entrevista estruturada. As entrevistas tiveram duração entre doze e vinte minutos, sendo todas realizadas no horário da educação física, dentro do ambiente da biblioteca. Horário este, que o espaço em questão encontrava-se vazio. Como forma de identificar os alunos, os mesmos por nossa sugestão escolheram nomes de personagens de filmes e desenhos infantis.

Os discursos produzidos nas entrevistas foram analisados à luz da análise de conteúdo que segundo Franco (2007) tem na mensagem, seja ela verbal ou escrita o seu ponto de partida. O lócus de nossa investigação foi a escola em que desenvolvemos nossa atividade docente, uma instituição de educação vinculada à rede municipal de educação de Teresina (PI), sediada na zona leste deste município.

\section{Análise e discussão dos dados: apresentando sentidos, apontando fragilidades}

Nas análises não consideramos somente os dados produzidos como produto final, mas todo o percurso de produção destes. Porquanto, não buscamos interpretar os desenhos elaborados pelos discentes e sim compreendê-los a partir de suas próprias explicações, ou seja, de suas próprias verbalizações.

Com exceção de apenas uma criança que relatou ter vivenciado em parte a situação grafada no desenho, todas as demais elaboraram suas produções gráficas pautadas em situações reais e vivenciadas pelos mesmos no ambiente em que nos propomos discutir. Este aspecto foi umas de nossas primeiras preocupações na pesquisa, relatar somente situações reais, já que como mencionado antes, os desenhos infantis nos apresentam duas nuances, o aspecto imaginário e o real, sendo este último, onde a criança demonstra através da sua produção aspectos situacionais embasados em experiências com o mundo, ou seja, demonstra o seu saber sobre o objeto de acordo com a concepção que desenvolveu. 
Por que eu não vou à biblioteca?: discursos, representações e sentimentos desvelados por sujeitos escolares através de desenhos

Em relação a isto, (VIEIRA, 2007, p. 22) afirma que "as experiências e o saber acumulado por meio delas contribuem para a capacidade humana de combinar os conhecimentos adquiridos, de maneira a construir novas realidades, significando-as, transformando-as em realidades conceituadas".

Nesse sentido, a seguir apresentamos as imagens elaboradas e explicadas pelos alunos à medida que foram solicitados a explicarem sobre seus desenhos.

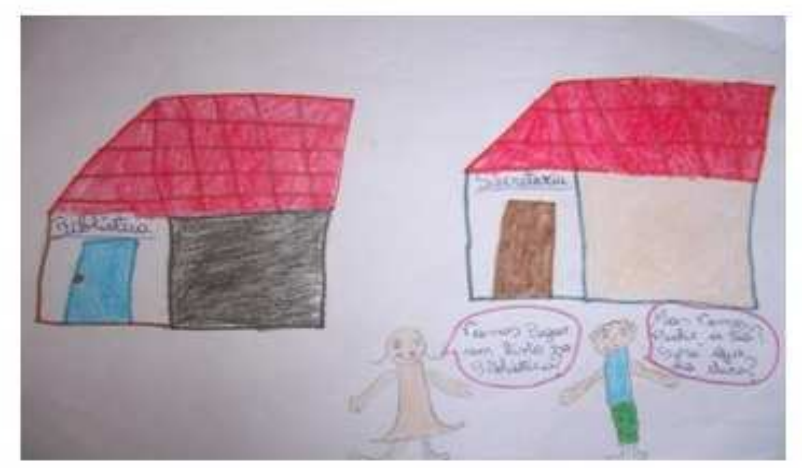

Desenho 1: Mulher Maravilha.

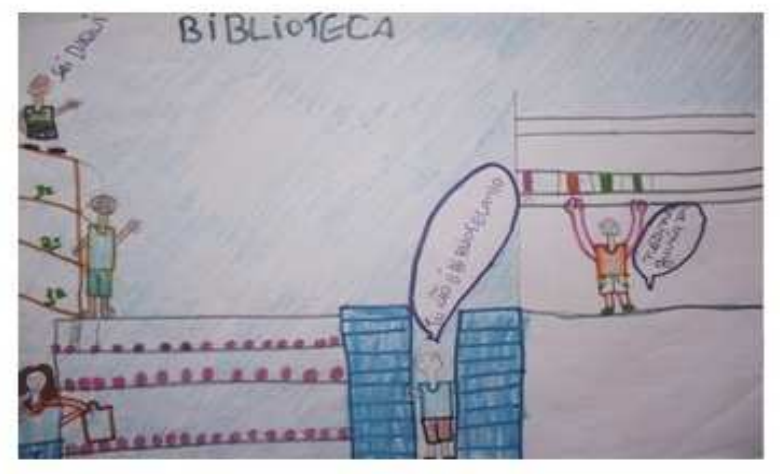

Desenho 2: Homem de Ferro.

Mulher Maravilha ao se retratar no desenho e dialogar com uma colega por meio de balões, põe em evidencia a questão do empréstimo de livros por meio de uma dúvida: Será que a tia deixa levar para casa?. A mesma ressalta a secretaria como o espaço para a permissão deste, o que nos faz inferir através da diferenciação das estruturas prediais, que a aluna não concebe os dois espaços grafados como únicos dentro de um contexto maior que é a escola e, principalmente, a biblioteca como responsável por este serviço. Em relação ao exposto, Silva (2009) compreende a biblioteca como a responsável pelo empréstimo das obras e afirma que a razão desta está diretamente relacionada ao empréstimo.

Homem de Ferro apresenta em seu desenho discursos como: Tu não é bibliotecário, Sai daqui e Não, mais queria ser. Embora retrate cinco sujeitos em sua produção, apenas dois são atuantes: um adulto (sexo masculino) e uma criança. Estes dois dialogam onde o adulto pede a saída da criança (Homem de ferro), afirmando que este último não é bibliotecário e a criança por sua vez rebate dizendo: Não, mais queria ser.

É interessante notar como Homem de Ferro se posiciona diante da argumentação trazida pelo adulto em seu grafismo. É curioso ainda pelo entendimento que este tem da profissão, mesmo esta não figurando entre aquelas que crianças na faixa etária do estudo escolhem, sejam em brincadeiras ou indagações a respeito de uma futura profissão. 
Lucas Veras de Andrade

Entretanto, a mesma é compreensível na medida que em nossas intervenções estamos sempre divulgando o trabalho deste profissional e buscamos incorporar nos alunos a noção de pertencimento do espaço, uma vez que o ambiente necessita, já que a instituição de ensino e a rede municipal de educação na qual estar vinculada não conta em seu quadro com profissionais bibliotecários e a maioria das escolas desta, não possuem responsáveis pelo ambiente da biblioteca, ficando este ao mero improviso.

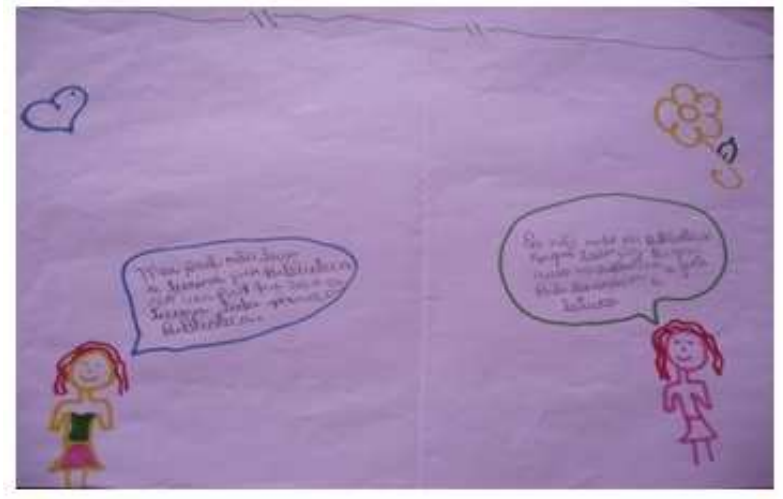

Desenho 3: Moranguinho.

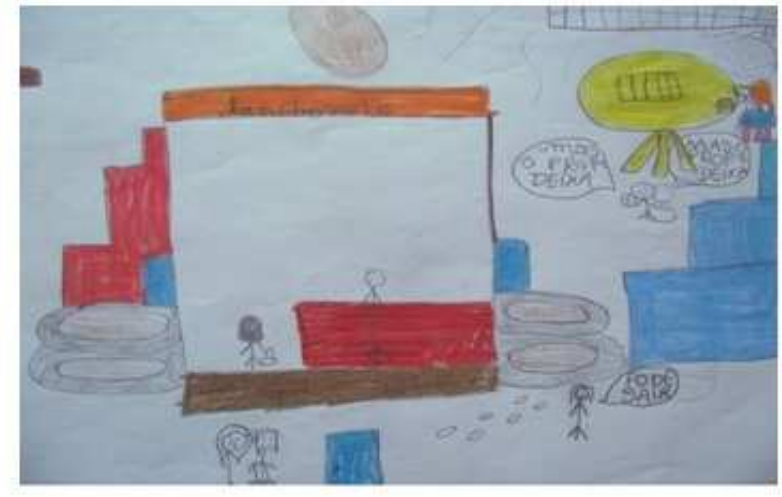

Desenho 4: Mônica.

Moranguinho apresenta duas meninas que dialogam problematizando a atitude dos professores por não levarem os alunos ao espaço da biblioteca. Moranguinho, ainda, afirmou que não visita o ambiente porque toda vez brigam. Mônica apesar de evidenciar várias crianças em seu desenho, no momento da explicação deste nos chamou atenção apenas para duas, observando que estas se sentiam entristecidas por não poderem frequentar o espaço.

Abaixo, em nossa observação inicial estas produções se ressaltaram pela forma como a aluna nos apresenta no grafismo.

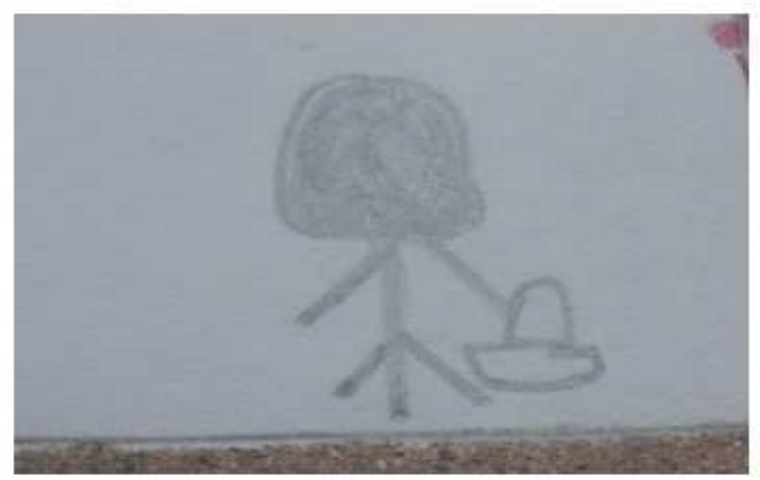

Desenho 4:Ausência de contorno no rosto.

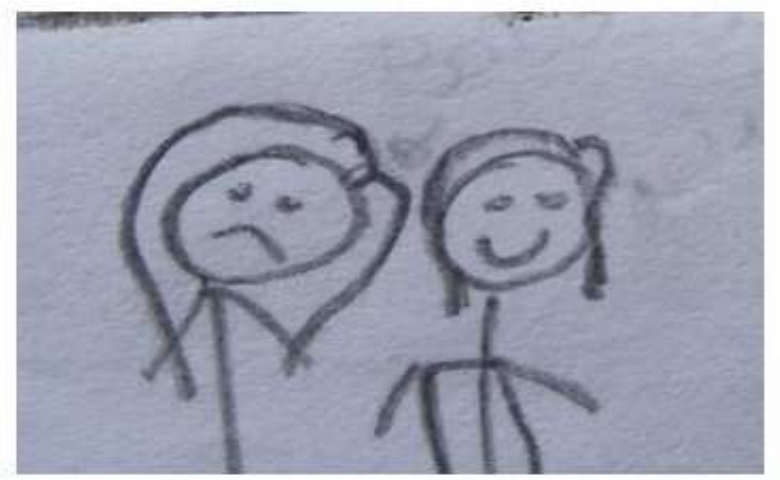

Desenho 4: Contorno da boca voltado para baixo.

A primeira foi desenhada com o rosto sem contornos e colorido de cor preta, enquanto que, a segunda apresenta o contorno da boca voltado para baixo, por isso questionamos a 
Por que eu não vou à biblioteca?: discursos, representações e sentimentos desvelados por sujeitos escolares através de desenhos

autora da produção no momento da entrevista. Mônica nos mostra ainda outras duas crianças que estão sentadas, expondo o seguinte discurso através do balão: Mas o prof. deixa, em resposta a uma figura de adulto (sexo feminino) que apresenta a seguinte fala em balão: Poder sair.

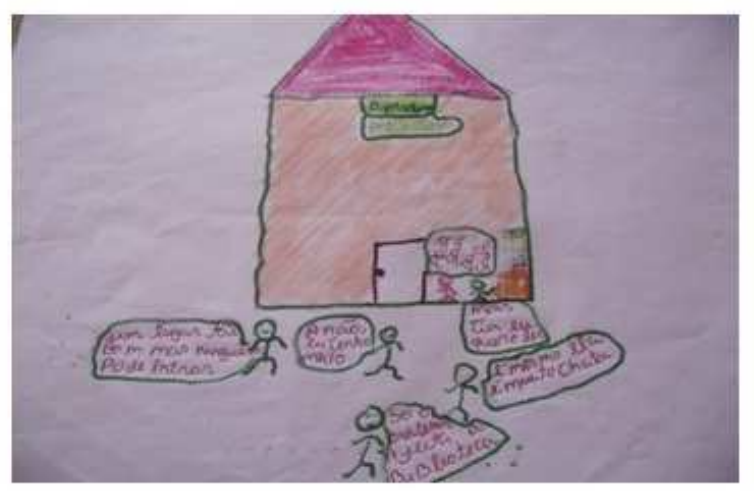

Desenho 5: Superman.

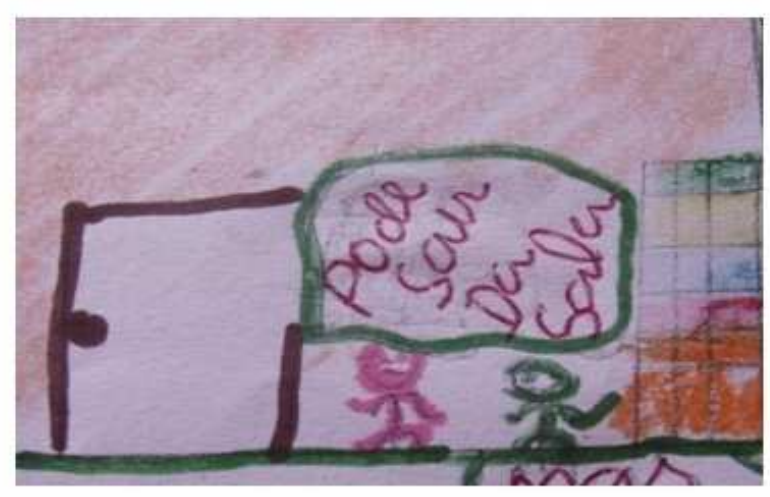

Desenho 5: Sujeitos que se diferenciam dos demais.

A exemplo de Homem de Ferro e Mônica, Superman pontua adultos em sua produção, no entanto, diferente dos outros dois que apresentam apenas uma figura, sendo um do sexo masculino no grafismo de Homem de Ferro e outro do sexo feminino na elaboração de Mônica, Superman evidencia adultos dos dois sexos ao mesmo tempo. Aspecto este que também pode ser observado na produção de Homem Aranha.

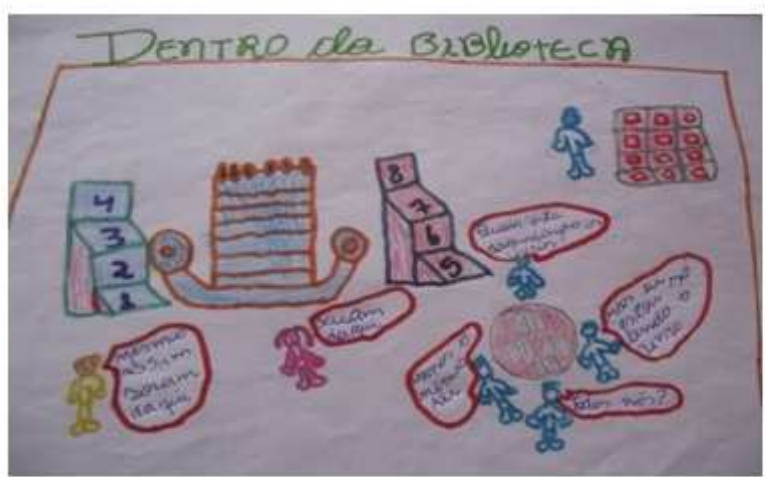

Desenho 6: Homem Aranha.

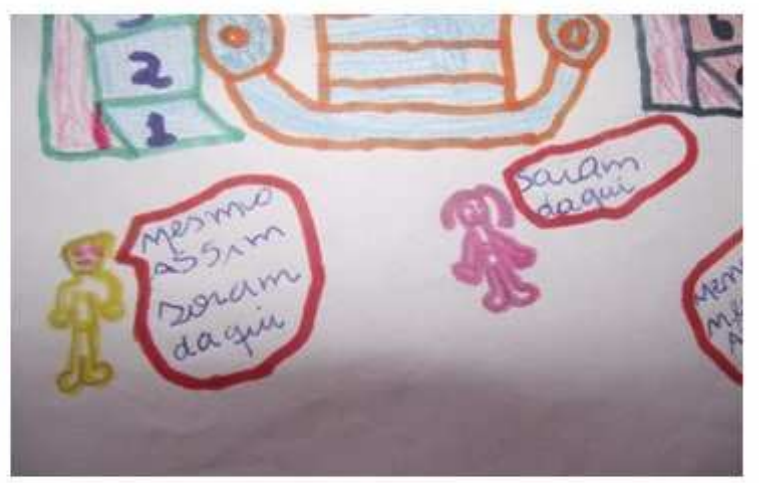

Desenho 6: Sujeitos que se diferenciam dos demais.

Diferente de Homem de Ferro e Mônica, Superman e Homem Aranha a nosso ver demonstram mais claramente a questão de gênero em suas produções, já que colorem tanto a figura masculina e feminina com cores socialmente internalizadas como cor de homem e cor de mulher, afirmação esta que pode ser embasada pelo discurso dos interlocutores em questão, quando foram instigados a responderem o porquê de terem pintado aqueles sujeitos com cor de rosa (mulher) e de verde ou amarelo (homem), como observarmos a seguir: 
Pesquisador: Porque você pintou este sujeito dessa cor?

Superman: Pintei de verde porque é cor de homem.

Homem Aranha: Ah, professor. Tudo da minha irmã é rosa, então rosa é cor de pintar mulher.

Outro aspecto a ser considerado nas produções destes dois alunos é como retratam a figura adulta no desenho. Além das cores diferenciadas dos demais retratados nas produções, ambos alocam estes dois em posição diferenciada, apresentando-os sempre afastados dos demais ou num nível superior, o que nos denuncia que sejam indivíduos que representam a autoridade dentro do contex to escolar.

Superman complementa seu desenho com discursos escritos em balões, representando um diálogo seu com amigos, expressando o seguinte: A biblioteca é um lugar bom, mas ninguém pode entrar, aspecto que demonstra o interesse em ler, assim como os colegas.

Homem Aranha amplia a descrição do seu desenho com discursos escritos. Apresenta em forma de diálogo resposta ao discurso dos sujeitos adultos acima mencionados, uma vez que ele expõe o discurso para estes: Saiam daqui: _Mais eu estou só lendo um livro e como resposta temos:_ Mesmo assim saiam daqui.

Neste recorte, percebemos claramente a insatisfação do aluno, tendo em vista que o mesmo argumenta no desenho suas intenções de usabilidade no espaço da biblioteca.

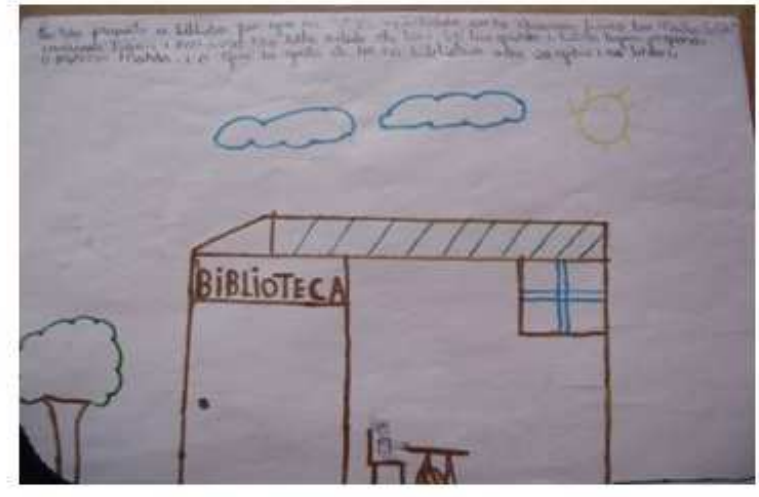

Desenho 7: Goku.

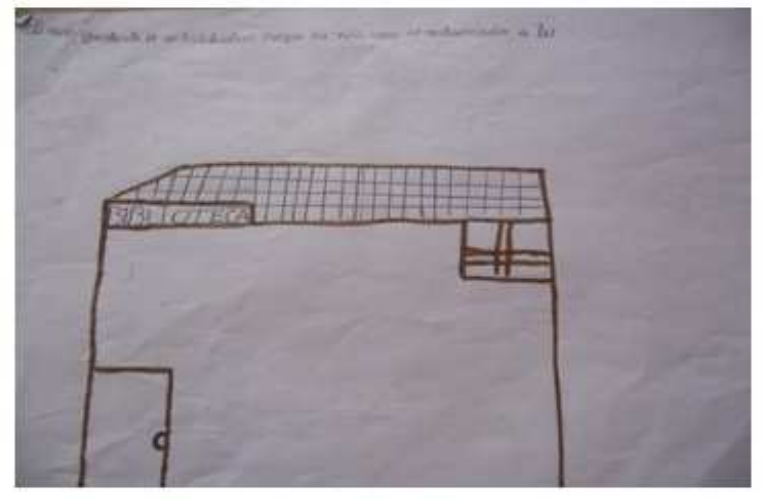

Desenho 8: Vegeta.

Vegeta e Goku se diferenciaram dos demais, uma vez que não coloriram com uma variação de cores os seus desenhos, entretanto, foram específicos em nos apresentar em forma de produção textual as motivações para tal atitude de não quererem frequentar a biblioteca. Vegeta nos apresenta o seguinte discurso: "Não frequento a biblioteca porque não sou acostumado a ler". Já Goku demonstra o seguinte: "Eu não frequento a biblioteca porque às vezes no intervalo ou na Educação Física tem muitas brincadeiras legais e por isso 
Por que eu não vou à biblioteca?: discursos, representações e sentimentos desvelados por sujeitos escolares através de desenhos

não tenho vontade de ir". Evidencia ainda "Só leio quando os livros são legais ou quando o professor manda".

Em uma análise inicial dos desenhos podemos demonstrar como fatores apontados pelos alunos: A vontade de levar livros para casa, ou seja, ausência de um empréstimo que é inferido pela dúvida colocada pela Mulher Maravilha. Outro aspecto enfatizado é a questão da proibição de alunos adentrarem no ambiente da biblioteca escolar, estando eles ou não neste espaço com o intuito de desenvolver competências e habilidades.

Relacionando estes dois aspectos, fica a pergunta em nós: de fato, qual o estímulo e o sentido que um aluno pode dar e ter ao frequentar uma biblioteca se não pode entrar e quando entra não pode permanecer e quando permanece não pode usufruir dos serviços que pode oferecer, como um empréstimo?

Outro fator que justifica a desmotivação na visão exposta é a postura docente de não levá-los ao ambiente em discussão. Em contrapartida, Mônica nos apresenta Mas o prof. deixa, o que nos permite inferir que mesmo os professores não os levando, existe um estímulo para que os mesmos a frequentem. Nesta conjuntura, apresenta-se o paradoxo para estas crianças, afinal há a permissão do professor versus o impedimento por parte de alguém.

O olhar das entrevistas: ampliando o discurso dos desenhos

$\mathrm{Na}$ entrevista, partimos do questionamento problematizador do nosso estudo: por que você não vai à biblioteca?. Neste como devolutiva, seis alunos apresentaram o impedimento por parte de alguém, o que converge com os desenhos apresentados por Mônica, Homem de Ferro, Homem Aranha e Supermam.

E, surpreendentemente, é sugerido por todos os citados acima que o impedimento é manifestado em maioria pelo setor gerencial da instituição, citando ainda zeladores, merendeiras e vigilantes. Fato questionável, porque no mundo hodierno, em que a cultura leitora é supervalorizada e a escola funciona como uma agência formadora em muitos casos, a gerência escolar devia no mínimo agir e partir da compreensão trazida por Balça e Fonseca (2012, p. 72-73) que menciona que a gestão escolar "deve estar ciente da importância de um serviço eficaz de biblioteca escolar, encorajar a sua utilização e assegurar uma equipe para a Biblioteca [...]". 
Ainda em relação à concepção que a direção enquanto líder educacional deve ter em relação à biblioteca, afirmamos que este deve compreendê-la como espaço educativo/cultural e, principalmente, como um ambiente fértil, passível de formar de leitores, ou como afirma Bastos, Almeida e Romão (2008, p.2-3) “[...] um ambiente que possibilita o acesso igualmente garantido a todos que buscam informações no contexto escolar, não centrando-se apenas nos estudantes, mas em toda a comunidade escolar envolvendo professores, alunos, pais, funcionários etc”.

Pela nossa experiência no lócus em questão, acreditamos que a direção tenha as concepções acima mencionadas, no entanto cremos e confirma-se pelos discursos de nossos interlocutores que o comportamento emitido por tais agentes educacionais ocorre em decorrência da vontade destes em garantir a manutenção da organização do espaço, como podemos observar em:

Pesquisador: Então você está querendo dizer que por causa da bagunça de um, todos são obrigados a sair da biblioteca?

Mônica: Sim. A tia fala que tem que estar tudo ajeitado.

Pesquisador: Porque você não frequenta o espaço da biblioteca?

Homem de Ferro: Eu não frequento porque muitas pessoas dizem para gente não entrar, porque não querem bagunça [...].

A organização do espaço é fundamental, sobretudo, quando se refere ao acervo, pois é através deste que teremos uma efetiva recuperação da informação, contudo, uma possível ausência organizacional não deve implicar no impedimento de uso e acesso estudantil à biblioteca.

Mônica amplia o universo de fatores desmotivantes e pontua na entrevista a falta de uma avaliação coerente por parte daqueles que impedem a frequência dos alunos na biblioteca, uma vez que o espaço quando frequentado, todos são incitados a sair, tanto aqueles que buscam conhecimento quanto aqueles que procuram estimular a desordem.

Pesquisador: Você fez várias crianças no espaço da biblioteca não foi? E algumas crianças se apresentam conversando através de diálogos, você sabe me dizer quem é cada criança dessa? O que você quis dizer colocando o desenho destas crianças?

Mônica: Sou eu e minhas amigas. Quis dizer que quando eu vou até lá, outras crianças entram para fazer bagunça, aí quando a tia vem, eu fico lendo... aí ela diz para todo mundo sair.

Esta mesma argumentação pode ser observada a seguir no discurso de Homem Aranha e Superman:

Pesquisador: Você colocou dentro de um balão a seguinte fala: Mesmo assim, saiam daqui, o que você quis dizer com isso?

Bibl. Esc. em R., Ribeirão Preto, v. 3, n. 2, p. 72-93, 2015. 
Por que eu não vou à biblioteca?: discursos, representações e sentimentos desvelados por sujeitos escolares através de desenhos

Homem Aranha: É quando as pessoas mandam a gente sair da biblioteca. O menino que tava lendo falou o que tava fazendo, e os que tava bagunçando também. Eles não acreditam muito na gente, aí manda sair todo mundo.

Superman pontua em seu discurso as reclamações da gestão institucional no ambiente da biblioteca, e não vê nestas problemas, entretanto, evidencia seu desprazer quando impedem aqueles que buscam o espaço pela aprendizagem.

Pesquisador: E que mal tem nisso, se a gestão reclama por algo que está errado?

Superman: Nenhum, o ruim é mandar sair todo mundo mesmo quem estava só lendo.

É interessante a capacidade e maturidade de compreensão que Superman nos apresenta em seu discurso, em saber que as reclamações manifestadas pela gestão não fazem mal, e inferimos que são até necessárias em virtude de como o espaço é utilizado pelos seus usuários.

Em consonância ao já exposto, e sobre como os discursos são colocados pelos discentes é constatado o uso aleatório e ausência de atividades no espaço, o que acarreta conflitos, principalmente, em relação àqueles alunos que procuram o espaço em questão. De fato a biblioteca deve se apresentar como um espaço democrático e no qual estes alunos têm o direito de frequentar e principalmente de utilizar seus serviços.

Além dos fatores elencados pelos alunos, demonstramos pela nossa vivência de quase três anos no lócus ainda dois aspectos. O primeiro a necessidade de um estudo de usuário que se busque saber as demandas e as necessidades informacionais dos alunos no intuito de compra de acervo que seja compatível aos seus interesses, já que como afirma Aguiar (2004), o ato de ler só é desenvolvido a partir do interesse do leitor.

E por último, e mais grave a formação do conceito de biblioteca que erroneamente é desenvolvido pelos alunos na instituição, uma vez que o espaço na escola tem seu uso desvirtuado para outras finalidades, longe do seu próprio conceito e fins.

Por exemplo, no ano de 2012 o espaço da biblioteca foi utilizado como depósito para os materiais de educação física e neste ano para o reforço escolar, ou seja, as crianças estão desenvolvendo a compreensão de que apenas frequenta aquele ambiente alunos com baixo rendimento escolar, o que minimiza o interesse daqueles que não se enquadram no perfil acima mencionado. Este tipo de concepção fragiliza o entendimento do ambiente da biblioteca e repercute sobre o entendimento das demais modalidades que o aluno possa se deparar futuramente. 
Lucas Veras de Andrade

Partindo dos questionamentos produzidos por nós a partir da análise inicial dos desenhos, buscamos compreender como os alunos veem o espaço da biblioteca a partir das experiências explicitas em suas produções. Nesse sentido, temos discursos de duas ordens. $\mathrm{O}$ primeiro em que os alunos compreendem o papel da biblioteca e reconhecem esse espaço como de aprendizagem e o outro que mesmo explícita a compreensão de biblioteca, não se percebe esse reconhecimento. Assim temos no primeiro grupo:

Mônica: A biblioteca é um lugar de sonhos, onde aprendemos e criamos várias coisas, histórias.

Superman: a biblioteca é um lugar bom, que pode levar uma criança ao auge. Que o conhecimento lá pode torná-lo em profissional.

Pesquisador: O que essa palavra auge que você disse, quer dizer?

Superman: Quero dizer ao sucesso da leitura e se lemos bem, também escrevemos bem.

Goku: [um lugar onde se] Pode fazer uma história e contá-la.

Moranguinho: É um lugar onde a gente desenvolve a leitura e ir mais que a leitura. Pesquisador: E o que é esse mais que a leitura?

Moranguinho: Muitas pessoas só leem a capa dos livros e os livros nos falam de dentro pra fora.

Mesmo em um ambiente que não favorece a compreensão do que seja uma biblioteca, suas possibilidades e serviços, podemos observar que os discentes se referem a esta como um ambiente potencializador de aprendizagens. No segundo grupo temos:

Homem Aranha: Um lugar tão bom, mas ninguém pode entrar.

Mulher Maravilha: A biblioteca é uma escuridão [...] não funciona como biblioteca, só representa uma biblioteca, [...] e ninguém pode ler.

É perceptível pelos discursos a descaracterização do espaço que discutimos e a pouca contribuição deste na vida escolar dos alunos. Mulher Maravilha se posiciona, criticamente, quando afirma que a biblioteca tem apenas o cunho representativo, que a nosso ver representaria a questão física.

Acreditamos que a mesma se posiciona desta maneira, por ter uma vivência em outra biblioteca (escola da prima). Além da participação minimizada para esta discente, inferimos que a biblioteca escolar para ela em sua escola não se configura como uma instância territorializada, já que apresentou em sua produção (desenho) o espaço da biblioteca de forma distinta dos demais ambientes da escola, o que também podemos inferir na maioria dos discursos produzidos pelos alunos, pois seu espaço físico não é acessível aos estudantes. 
Por que eu não vou à biblioteca?: discursos, representações e sentimentos desvelados por sujeitos escolares através de desenhos

Em relação aos sentimentos que emergem em função da realidade vivenciada pelos alunos frente à biblioteca podemos afirmar a existência de uma ambivalência de sentimentos, ou seja, alunos que mesmo diante das adversidades no espaço desenvolvem sentimentos positivos, além de outros que se manifestam negativamente.

Destacamos, ainda, que os sentimentos explícitos foram expressos tanto nas cores utilizadas nos desenhos como no traçado gráfico em algumas produções como pode ser evidenciado na elaboração de Mônica e ratificados nos discursos proferidos nas entrevistas. Nesse sentindo, categorizamos os discursos em três grupos, o primeiro em que os discentes se apresentam apenas de forma negativa, o segundo de forma positiva e o terceiro em que os estudantes apresentam ao mesmo tempo os dois sentimentos. Assim no primeiro grupo temos:

Pesquisador: Você desenhou uma menina... Correto? Sim ou não?

Mônica: Sim.

Pesquisador: O rosto dela está pintado de preto, o que isto quer dizer?

Mônica: Ela está dentro da biblioteca querendo lê e quando ela vai lá a tia manda ela sair e ela se sente muito mal.

Pesquisador: Essa menina é você?

Mônica: Sim.

Pesquisador: Então você ta querendo dizer que esta cor preta no rosto da menina representa um sentimento de mal-estar, um desconforto seu a ir à biblioteca e ouvir para sair de lá?

Mônica: Sim, porque quando eu vou à biblioteca eu quero ler e aprender várias coisas e quando eu entro já é sabendo que não vou ficar.

É nítido o sentimento negativo manifestado por Mônica, entretanto, este a nosso ver é muito mais em função da atitude de impedimento da pessoa que ela denomina de tia do que ao não oferecido a ela no espaço da biblioteca, diferente de Vegeta.

Pesquisador: Como sente em relação à biblioteca?

Vegeta: Eu não gosto dela não, não sou acostumado a ler. Na minha casa eu não tenho livro.

Vegeta demonstra seu desprazer em função da falta de uma cultura leitora, o que implica em uma ausência de sentido para a existência de uma biblioteca, além disso, pontua o aspecto familiar quando menciona que não tem livros em casa. Diante de sua argumentação, evidenciamos o papel fundamental deste ambiente no processo de incentivo, desenvolvimento e formação do estudante como aluno e leitor.

Nossa afirmação encontra arcabouço em Rigoleto e Di Giorgi (2009), quando afirma que a família é considerada como um grande parceiro neste percurso de formação acadêmica do aluno e da própria biblioteca escolar. 
Lucas Veras de Andrade

Os autores ainda pontuam que cabe a família inserir a criança no mundo das letras e da leitura por meio do incentivo e a disponibilização de material e para a escola fica a incumbência de ofertar espaços de leituras e que nestes sejam desenvolvidas atividades que almejem a formação de leitores, leitores estes capazes de agirem, refletirem e reagirem diante da informação. No segundo grupo temos:

Pesquisador: Como você enxerga a biblioteca da escola?

Superman: Vejo como um lugar que eu possa tirar um monte de vantagens para mim.

Pesquisador: Então o seu sentimento em relação à biblioteca é bom?

Superman: Hum rum.

Pesquisador: Mesmo sendo impedido de entrar pelas pessoas que você citou?

Superman: Hum rum.

Pesquisador: Qual o seu sentimento em relação à biblioteca?

Goku: Eu gosto de ler na biblioteca.

Pesquisador: Você gosta da biblioteca?

Homem de Ferro: Sim.

Pesquisador: Por quê?

Homem de Ferro: Não sei, não sei dizer. Só sei que eu gosto.

Os discursos apresentados não nos fornecem subsídios que permitam a compreensão das motivações para o desenvolvimento de sentimentos positivos por parte dos alunos frente ao ambiente da biblioteca, entretanto, nos fazem hipotetizar que assim como Mulher Maravilha que em seu discurso nos apresentou a vivência com outra biblioteca, o que lhe proporcionou um olhar diferenciado sobre este espaço, estes alunos possivelmente também tenham tido, uma vez que a construção conceitual a respeito de um objeto só é construída a partir de uma situação vivenciada e sendo a situação discutida demonstrada sobre condições adversas, porquanto é no mínimo curiosa a construção conceitual destes alunos sobre o espaço, apenas a partir da vivência da biblioteca da instituição em análise.

Por último temos o grupo em que é percebida a existência no discurso dos dois sentimentos ao mesmo tempo, assim observamos:

Pesquisador: Esse vermelho no rosto do menino que você desenhou lendo significa o quê?

Homem Aranha: raiva.

Pesquisador: E você como se sente com isto?

Homem Aranha: mal porque causa do menino que ler e tem que sair por causa da bagunça $[. .$.

Pesquisador: Você gosta de ir à biblioteca?

Homem Aranha: Gosto.

Pesquisador: Por quê?

Homem Aranha: Por que lá é bom, aprendemos muita coisa. Aprendemos a ler, a escrever.

Bibl. Esc. em R., Ribeirão Preto, v. 3, n. 2, p. 72-93, 2015. 
Por que eu não vou à biblioteca?: discursos, representações e sentimentos desvelados por sujeitos escolares através de desenhos

Homem Aranha representa, simbolicamente, seu sentimento negativo mediante a cor vermelha quando colore os olhos de uma criança em seu desenho. Em relação o significado das cores, Freitas (2007) pontua três fatores que corroboram para a escolha de uma cor, sendo eles: fisiológicos, psicológicos e sociológicos. Entretanto, "a escolha de uma cor, algumas vezes se determina não por preferências pessoais, mas pela utilização que ela poderá ter em função de algo" (FREITAS, 2007, p. 4).

Desta forma, estabelecemos um elo entre produção e o discurso do aluno, a cor utilizada pelo mesmo vai ao encontro perfeitamente do significado estabelecido pela autora que tem no vermelho na perspectiva afetiva entre outros significados, a violência e agressividade. A partir desta definição, enquadramos a coloração preta demonstrada na produção de Mônica que tanto na perspectiva da autora quanto da discente representam tristeza e melancolia.

Em contrapartida observamos sentimentos contrários ao analisado, anteriormente, no discurso de Homem Aranha, enquadrando este também no grupo em que pontuamos os sentimentos positivos. A seguir teceremos algumas considerações e apresentamos algumas inconclusões passíveis de estudos posteriores, já que os discursos dos sujeitos escolares evidenciaram a necessidade de ampliar e aprofundar discussões que no percurso da nossa investigação emergiram.

\section{Tecendo algumas considerações e (In)certezas}

No decorrer de nossa investigação a todo o momento pincelamos algumas considerações acerca dos aspectos levantados nas categorias de análise, no entanto, se faz necessário apresentar algumas notas a um nível conclusivo. O espaço como evidenciado não contribui para uma educação formativa, só propaga a ideia de um espaço sem público e descomprometido com atividades pedagógicas da escola.

A instituição analisada não apresenta um trabalho integrado na proposta do tripé sala de aula/biblioteca/instituição escolar, assim como o bibliotecário e o professor, que se justifica pela ausência do primeiro na escola e na rede educacional pública do município de Teresina como um todo. As consequências disto são: a fragilização e dificuldade da disseminação da leitura, conhecimento e o desenvolvimento de várias competências no alunado, uma vez que entendemos que o trabalho docente somente em sala de aula não supre 
Lucas Veras de Andrade

todas as necessidades de formação que a sociedade da informação requer do estudante no contexto atual.

Defendemos com base em nossa experiência, a presença de um profissional responsável pelo local e com formação específica, pois compreendemos que somente esse é capaz em função da sua formação, modificar a triste realidade que se depara as bibliotecas escolares, pois as figuras que estão à frente destes espaços, em maioria, professores em processo de aposentadoria ou afastados de sala por motivos de saúde, propagam o paradigma ultrapassado de guardião do espaço e do silêncio, o que minimiza o entendimento das finalidades deste ambiente para os alunos.

Enquanto professores devemos rever nossas práticas, no intuito de trabalharmos em nós os leitores que gostaríamos que nossos alunos fossem, e principalmente, ser o elo entre a biblioteca e os discentes, pois podemos ser as únicas formas de acesso a esse espaço e aos livros para os alunos. No que compete às concepções de biblioteca, embora esta se demonstre em condições desfavoráveis de compreensão, a maioria dos discursos se posicionam, positivamente, nos fazendo inferir como um local agradável e similar a um lugar de leitura. Este aspecto embasa o que falamos sobre a fragilização do conceito de biblioteca pelos alunos, uma vez que uma biblioteca oferece algo que está além de um espaço de leitura.

Nossa investigação buscou apresentar o desenho como uma representação simbólica repleta de significações resultantes das experiências vivenciadas por nossos interlocutores no ambiente da biblioteca escolar, o que permitiu aos membros da instituição reconhecer suas práticas na medida em que apresentamos os dados produzidos e analisados por meio de uma roda de conversa, onde estiveram presentes professores e direção. Por meio desta foi possível gerar processos de subjetivação que permitiu uma reflexão de todos os presentes a ponto de avaliarem como estes comportamentos apresentados pelos alunos contribuem ou não para se atingir os objetivos escolares, a fim de que sejam ressignificados.

Pretendemos com nossa pesquisa proporcionar momentos de ponderação sobre o espaço da biblioteca escolar, e sugerir ideias para que este local seja utilizado e visto como um ambiente de prazer e lazer, pois como dito, esse aspecto demonstrou-se como um reclamo dos discentes. Desse modo, apresentamos para a equipe a partir de Andrade et al. (2013) atividades lúdicas, ou seja, atividades voltadas para o aprender brincando no ambiente da biblioteca. 
Por que eu não vou à biblioteca?: discursos, representações e sentimentos desvelados por sujeitos escolares através de desenhos

A confiança na mudança da realidade não temos. Porém, realidades como a apresentada se evidenciará diferente quando de fato o espaço discutido estiver consolidado ao projeto educativo da escola e obtiver o reconhecimento pelos seus dirigentes como um espaço de estudo, acesso a informação e ao conhecimento.

Apesar de percebemos discursos frágeis no momento do círculo de conversa a ponto de ficarmos na dúvida sobre mudanças diante do exposto, despontamos esperançosos, pois um caminho foi delineado para alterar o quadro exposto; cabendo à instituição escolar pensar estrategicamente as mudanças.

Agradecimentos: Aos meus queridos alunos, por me proporcionarem reflexões incomensuráveis no meu fazer pedagógico cotidiano, em especial as turmas do $5^{\circ}$ ano. A gestão da instituição de análise por me possibilitar utilizar o espaço como lócus de pesquisa. Ao amigo e colega de Profissão Prof. Michel Machado pela escuta e reclamo no percurso deste estudo, assim como os demais companheiros: Jéssica Lia, Helison Daniel e Rosana Carvalho, que pelas minhas inquietudes de pesquisa me denominam de Professor Pesquisador. 


\section{Referências}

AGUIAR, V. T. A formação do Leitor. In: CECCANTINI, J. L. C.T; PEREIRA, R.F; ZANQUETA JUNIOR, J. (Org.) Pedagogia cidadã: cadernos de formação (Língua Portuguesa). São Paulo: UNESP, Pró-Reitoria de Graduação, 2004. v. 2. p.17-30.

ANDRADE, L. V. et al. Os livros entre as cores e a conscientização de professores para o uso da biblioteca escolar. Bibl. Esc. em Rev., Ribeirão Preto, v. 2, n. 1, p. 69-88, 2013.

BALÇA, A; FONSECA, M. A. Os docentes e a biblioteca escolar: uma relação necessária. Revista Lusófona de Educação, Lisboa, v. 2, n. 20, p. 65-80, 2012.

BASTOS, G. G; ALMEIDA, L.; ROMÃO, L. M. S. Os sujeitos-escolares e a biblioteca: um estudo discursivo. Biblios, Perú, v. 33, p. 1-10, 2008

FERREIRA, S. Imaginação e linguagem no desenho da criança. Campinas: Papirus 2001.

FRANCO, M. L. P. B. Análise de Conteúdo. 2. ed. Brasília: Liber Livro, 2007.

FREITAS, A. K. M. Psicodinâmica das cores em comunicação. Núcleo de Comunicação, Limeira, v. 4, ano 12, p.11-18, 2007.

LIMA, M. C. B; CARVALHO, A. M. P. O desenho infantil como instrumento de avaliação da construção do conhecimento físico. Revista Electrónica de Enseñanza de las Ciencias, v. 7, n. 2, p. 337-348, 2008.

LÜDKE, M; ANDRÉ, M. E. D. A. Pesquisa em educação: abordagens qualitativas. São Paulo: EPU, 1986.

NATIVIDADE, M. R.; COUTINHO, M. C; ZANELLA, A. V. Desenho na pesquisa com crianças: análise na perspectiva histórico-cultural. Contextos Clínicos, São Leopoldo, v. 1, n. 1, jan./jun., p. 9-18, 2008.

SILVA, R. J. Biblioteca escolar: organização e funcionamento. In: SOUZA, R. J. (Org.). Biblioteca Escolar e Práticas Educativas: o mediador em formação. Campinas: Mercado de Letras, 2009. p. 115-134.

SILVA, J. M. M. O desenho na expressão dos sentimentos em crianças hospitalizadas. Fractal: Revista de Psicologia, Niterói, v. 22, n. 2, p. 447-456, maio/ago. 2010.

RIGOLETO, A. P. C; DI GIORGI, C. A. G. Outros parceiros na biblioteca escolar: democratização e incentivo à leitura. In: SOUZA, R. J. (Org.). Biblioteca escolar e práticas educativas: o mediador em formação. Campinas: Mercado de Letras, 2009. p. 219-237.

VIEIRA, L. F. O processo de significação do desenho infantil. 2007. 72 f. Trabalho de Conclusão de Curso (Graduação em Licenciatura Plena em Pedagogia) - Centro de Educação e Ciências Humanas, Universidade Federal de São Carlos, São Carlos. 2007.

VYGOTSKI, L. S. La imaginación y el arte en la infancia. 4. ed.. Madrid: Akal, 1998. 